\title{
ANALISIS PERBANDINGAN ANTARA HIBRID RSA DENGAN AMELSBR DAN HIBRID TRANSPOSISI KOLOM DENGAN AMELSBR
}

\author{
Wamilliana $^{1}$, Ardiansyah ${ }^{2}$, dan Arif Al Furqon ${ }^{2}$ \\ ${ }^{1}$ Jurusan Matematika, Fakultas Matematika dan Ilmu Pengetahuan Alam, Universitas Lampung \\ ${ }^{2}$ Jurusan Ilmu Komputer, Fakultas Matematika dan Ilmu Pengetahuan Alam, Universitas Lampung \\ Email: wamiliana.1963@fmipa.unila.ac.id
}

\begin{abstract}
ABSTRAK
Technology makes communication better, not limited by place and time. The form of communication that is often used is sending and receiving messages. This demands a strong security system. Cryptographic method is one way to secure messages by changing the form of messages so that they are difficult to understand. In addition, the method of steganography is a way to hide messages into the container media. Cryptography and steganography make the security of a message better. In this study a comparison between RSA cryptography (Rivest Shamir Adleman) and cryptographic transposition columns inserted into the container media using AMELSBR (Adaptive Minimum Error Least Significant Bit Replacement) steganography, with the container media in the form of images with the extension. JPG as input (cover image), and produces output .JPG (stegoimage). The conclusion obtained from this study is that the ciphertext transposition column has a faster time in the insertion process and produces a smaller stegoimage than the RSA ciphertext. But RSA ciphertext is more resistant to image cutting treatment than column ciphertext transposition. Some social media can send stegoimage perfectly if there is no compression process performed.
\end{abstract}

Kata kunci : kriptografi, steganografi, RSA, transposisi kolom, AMELSBR, hibrid, JPG, brightness, contrast, crop, media sosial.

\section{PENDAHULUAN}

Berkembangnya teknologi membuat cara setiap individu berinteraksi berubah. Perubahan yang jelas terlihat adalah bentuk komunikasi. Bentuk komunikasi yang sering digunakan adalah mengirim dan menerima pesan. Untuk menghindari kemungkinan pesan dicuri pihak lain dapat dilakukan dengan memodifikasi pesan. Bentuk penanganan masalah keamanan informasi dan data ini adalah dengan menggunakan metode kriptografi.

Kriptografi merupakan metode untuk mengirimkan pesan secara rahasia[2]. Metode kriptografi dapat mengubah pesan rahasia menjadi pesan acak (ciphertext). Namun, kecurigaan akan timbul saat seseorang mengirimkan pesan secara acak kepada orang lain. Terdapat sebuah metode untuk melindungi pesan rahasia dari kecurigaan pelaku kejahatan adalah dengan menggunakan steganografi.

Steganografi merupakan teknik menyembunyikan pesan rahasia pada suatu media sehingga keberadaan pesan rahasia tidak disadari oleh pihak lain[3]. Kelebihan yang dimiliki teknik steganografi terletak pada pesan yang tersembunyi di dalam sebuah media penampung (cover object) dan tidak terlihat secara langsung sehingga mengurangi kecurigaan terhadap pesan. Namun, penggunaan teknik ini secara langsung pada pesan rahasia tidak menjamin pesan terlindungi dari pelaku kejahatan.

Pilihan terbaik yang dapat digunakan untuk mengirim suatu pesan adalah dengan menggunakan kombinasi antara kriptografi dan steganografi. Teknik kriptografi berperan untuk menyandikan pesan menjadi pesan acak (ciphertext) kemudian teknik steganografi berperan untuk menyisipkan pesan acak kedalam sebuah media penampung (cover object).

Metode kriptografi RSA (Rivest Shamir Adleman) [1] dan metode kriptografi transposisi kolom [4] adalah dua metode yang dapat digunakan untuk menyandikan pesan. Sedangkan metode 
steganografi AMELSBR (Adaptive Minimum Error Least Significant Bit Replacement) adalah metode untuk menyisipkan pesan kedalam sebuah media penampung [5]. Pada [6] metode AMELSBR diaplikasikan dengan menggunakan file JPG/JPEG sebagai cover dan PNG sebagai stegoimage.

Pada penelitian ini akan dilakukan perbandingan kedua metode kriptografi transposisi kolom dan RSA saat dilakukan penyisipan menggunakan metode steganografi AMELSBR dengan media penampung berupa gambar sebelum penyisipan .JPG dan setelah penyisipan juga tetap menghasilkan gambar.JPG.

\section{METODE PENELITIAN}

Penggunaan gambar yang memiliki ekstensi .JPG sebgai input dan output karena mudahnya mendapatkan gambar jenis ini, baik dari kamera digital, smarthphone, maupun dari internet.

Metode penelitian yang dilakukan untuk mendapatkan hasil perbandingan dari masing-masing teknik kriptografi. Sebelumnya, pesan disandikan menjadi pesan acak (ciphertext). Kemudian, menyisipkan ciphertext kedalam media penampung untuk mendapatkan stegoimage. Setelah itu, stegoimage dilakukan beberapa perlakuan seperti perubahan brightness, perubahan contrast, pemotongan gambar, dan pengiriman melalui media sosial. Selanjutnya, dilakukan proses ekstraksi pada stegoimage untuk mendapatkan berkas ciphertext. Terakhir, dilakukan proses dekripsi pada setiap kriptografi RSA dan transposisi kolom. Berikut ini skenario pengujian yang dilakukan.

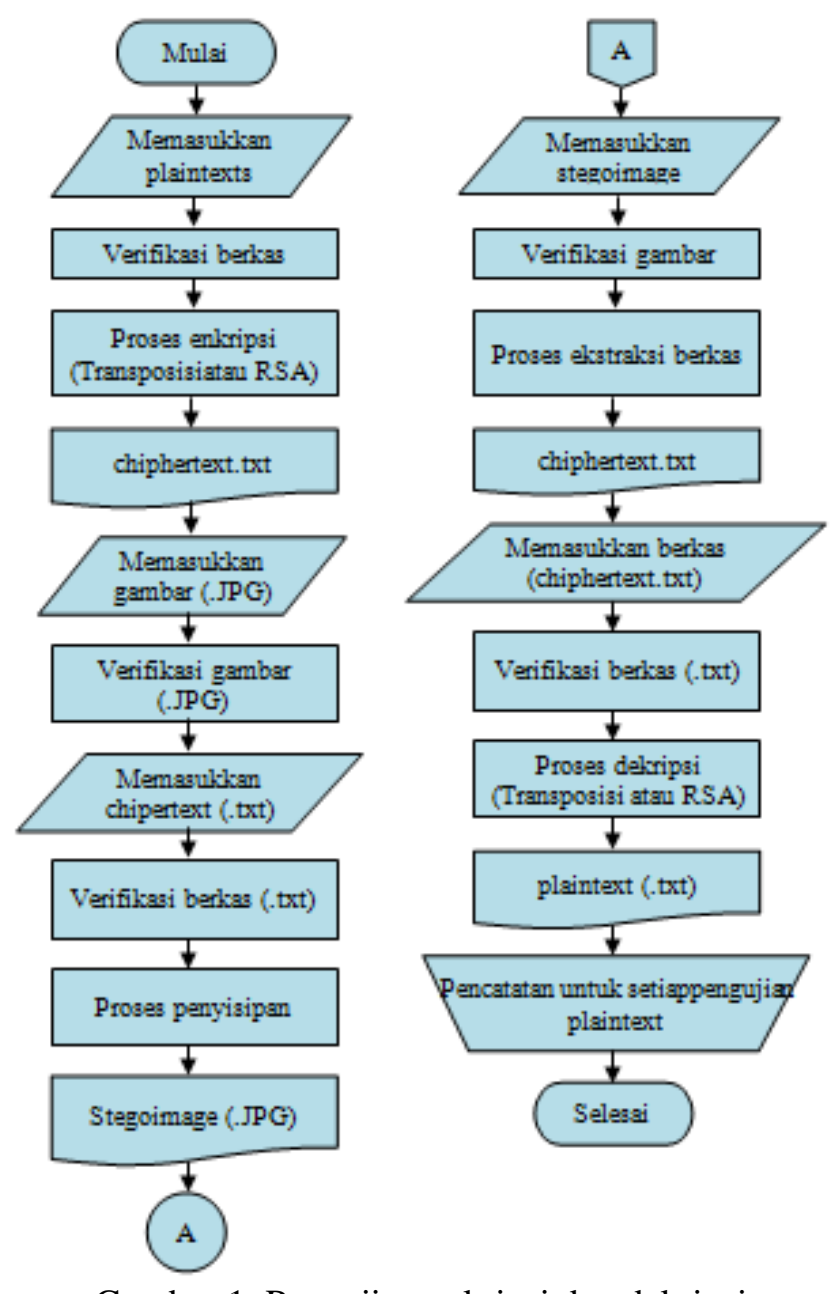

Gambar 1. Pengujian enkripsi dan dekripsi 
Pertama, pengujian untuk membuktikan apakan proses enkripsi kriptografi mempengaruhi hasil dari ekraksi stegoimage pada setiap ciphertext kriptografi RSA dan transposisi kolom. Kedua, pengujian untuk mendapatkan waktu proses penyisipan pada ciphertext RSA dan chipertext transposisi kolom. Ketiga, pengujian untuk membuktikan gambar dengan ekstensi .JPG dapat digunakan sebagi input dan output. Keempat, pengujian untuk membuktikan perubahan brightness dan contrast mempengaruhi isi pesan di dalam stegoimage. Kelima, pengujian untuk membuktikan pengaruh pemotongan gambar pada pesan di dalam stegoimage. Keenam, pengujian untuk membuktikan pengaruh pengiriman stegoimage melalui media sosial.

\section{HASIL PENELITIAN}

Gambar yang digunakan sebagi media penampung berasal dari kamera smartphone. Gambar memiliki ekstensi .JPG dapat dilihat pada Tabel 1.

Tabel 1. Gambar media penampung

\begin{tabular}{|c|c|c|c|c|}
\hline No & $\begin{array}{c}\text { Warna } \\
\text { Dominan }\end{array}$ & Gambar & $\begin{array}{l}\text { Resolusi } \\
\text { (pixel) }\end{array}$ & $\begin{array}{l}\text { Ukuran } \\
\text { (bytes) }\end{array}$ \\
\hline 1 & Biru & & $\begin{array}{c}3264 x \\
2448\end{array}$ & 580,317 \\
\hline 2 & Fullcolor & & $\begin{array}{c}3264 x \\
2448\end{array}$ & $1,447,307$ \\
\hline 3 & Grayscale & & $\begin{array}{c}3264 x \\
2448\end{array}$ & 514,764 \\
\hline 4 & Hijau & & $\begin{array}{c}3264 x \\
2448\end{array}$ & 932,416 \\
\hline 5 & Hitam & 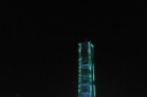 & $\begin{array}{c}3264 x \\
2448\end{array}$ & 527,364 \\
\hline
\end{tabular}




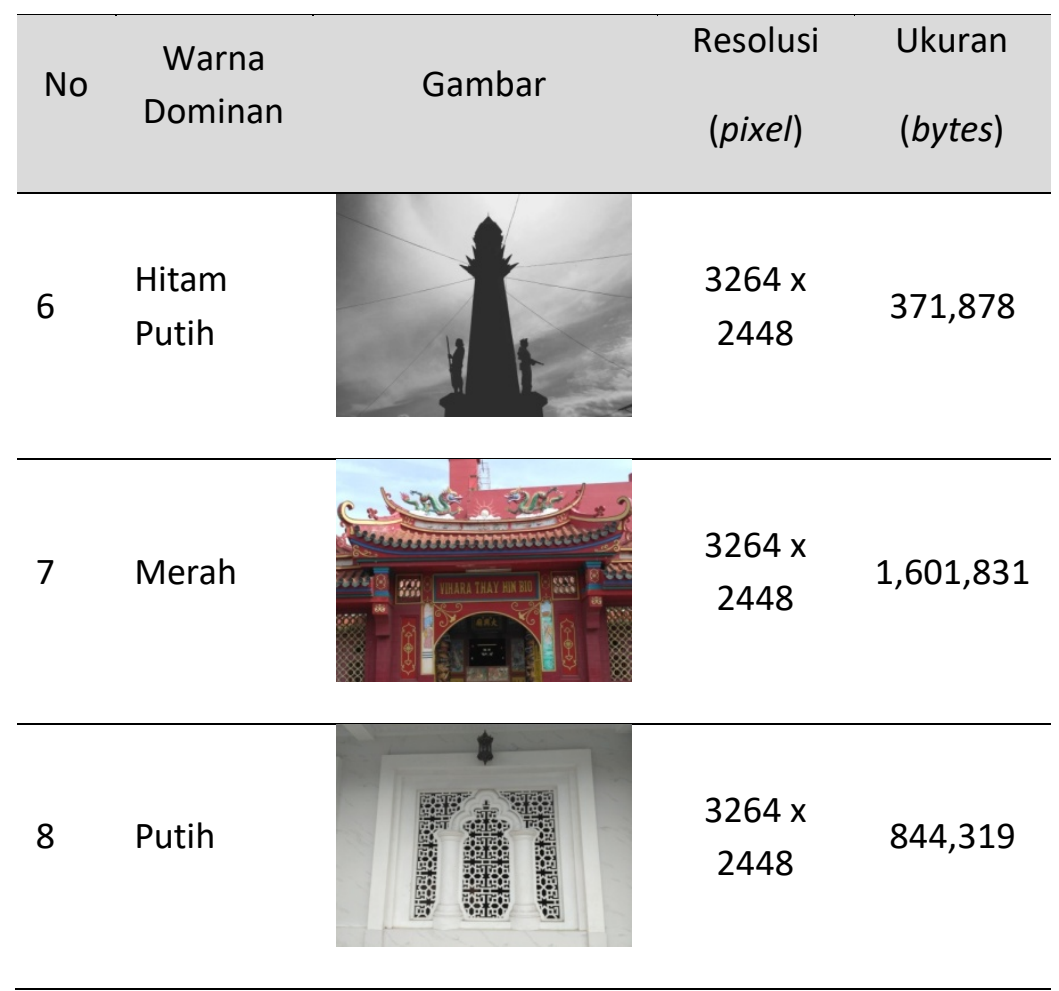

Media penampung disipkan pesan dengan beberapa banyaknya karakter yaitu, pesan dengan 85 karakter, 299 karakter, 883 karakter, 2838 karakter, dan 5759 karakter. Alasan dipilih beberapa banyak karakter untuk memberikan hasil persentasi keberhasilan setiap metode pada pengujian.

Tabel 2. Hasil enkripsi dan dekripsi RSA

\begin{tabular}{lllllll}
\hline \multirow{2}{*}{ WARNA } & \multicolumn{6}{c}{ RSA } \\
\cline { 2 - 7 } & \multicolumn{2}{c}{883 karakter } & 2838 karakter & 5759 karakter \\
\cline { 2 - 7 } Hasil & $(\%)$ & Hasil & $(\%)$ & Hasil & $(\%)$ \\
\hline Fullcolor & Berhasil & 100 & Berhasil & 100 & Berhasil & 100 \\
\hline Grayscale & Berhasil & 100 & Berhasil & 100 & Berhasil & 100 \\
\hline Hijau & Berhasil & 100 & Berhasil & 100 & Berhasil & 100 \\
\hline Hitam & Berhasil & 100 & Berhasil & 100 & Berhasil & 100 \\
\hline Hitam Putih & Berhasil & 100 & Berhasil & 100 & Berhasil & 100 \\
\hline Merah & Berhasil & 100 & Berhasil & 100 & Berhasil & 100 \\
\hline Putih & Berhasil & 100 & Berhasil & 100 & Berhasil & 100 \\
\hline
\end{tabular}

Tabel 3. Hasil enkripsi dan dekripsi transposisi kolom

\begin{tabular}{lcccccc}
\hline \multirow{2}{*}{ WARNA } & \multicolumn{7}{c}{ Transposisi Kolom } \\
\cline { 2 - 7 } & \multicolumn{2}{c}{883 karakter } & \multicolumn{2}{c}{ 2838 karakter } & 5759 karakter \\
\cline { 2 - 7 } & Hasil & $(\%)$ & Hasil & $(\%)$ & Hasil & $(\%)$ \\
\hline Biru & Berhasil & 100 & Berhasil & 100 & Berhasil & 100 \\
\hline Fullcolor & Berhasil & 100 & Berhasil & 100 & Berhasil & 100 \\
\hline Grayscale & Berhasil & 100 & Berhasil & 100 & Berhasil & 100 \\
\hline Hijau & Berhasil & 100 & Berhasil & 100 & Berhasil & 100 \\
\hline Hitam & Berhasil & 100 & Berhasil & 100 & Berhasil & 100 \\
\hline
\end{tabular}


(C2018 Ilmu Komputer Unila Publishing Network all right reserve

\begin{tabular}{lllllll} 
Hitam Putih & Berhasil & 100 & Berhasil & 100 & Berhasil & 100 \\
\hline Merah & Berhasil & 100 & Berhasil & 100 & Berhasil & 100 \\
\hline Putih & Berhasil & 100 & Berhasil & 100 & Berhasil & 100 \\
\hline
\end{tabular}

Setelah dilakukan pengujian, berkas pesan dapat kembali sempurna walaupun telah melewati proses enkripsi-penyisipan-ekstraksi-dekripsi. Hal ini menunjukkan RSA dan transposisi kolom dapat digunakan untuk proses penyisipan.

Pada pengujian waktu dilakukan dapat diambil kesimpulan bahwa transposisi kolom memiliki waktu lebih cepat 1-2\% daripada RSA. Hal ini sebanding dengan ciphertext yang dienkripsi oleh RSA lebih besar ukuranya, sehingga membutuhkan waktu penyisipan atau ekstraksi lebih lama.

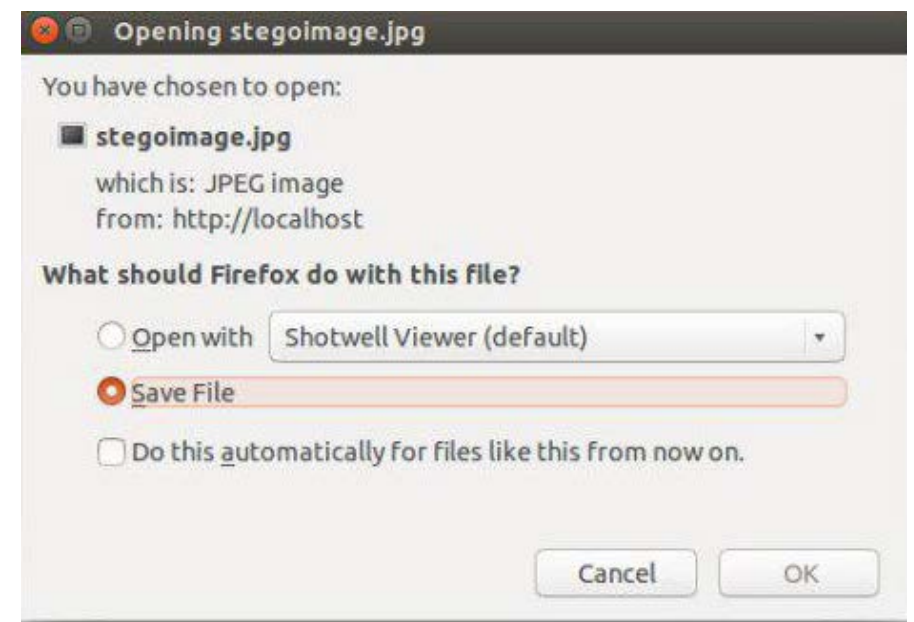

Gambar 2. Output stegoimage ekstensi .JPG

Penggunaan output ekstensi .JPG dapat beresiko kepada hilangnya pesan di dalam media penampung, tetapi resiko dapt dikurangi dengan mengubah tipe file stegoimage pada.PNG atau tipe lossless compression lainya, tetapi tetap menggunakan ekstensi .JPG sebagai output.

Pada pengujian perubahan brightness dan contrast yang menggunakan file dengan ekstensi .JPG tidak dapat mengembalikan pesan sama sekali, karena penurunan ukuran saat proses manipulasi brightness maupun contrast.

Tabel 4. Hasil pemotongan gambar RSA

\begin{tabular}{clccccc}
\hline \multirow{2}{*}{$\begin{array}{c}\text { Pemotongan } \\
\text { Kanan }\end{array}$} & Hasil & \multicolumn{5}{c}{ Karakter } \\
\cline { 3 - 7 } & & 85 & 299 & 883 & 2838 & 5759 \\
\hline \multirow{2}{*}{$1 / 8$} & Berkas & Kembali & Sebagian & Sebagian & Sebagian & Sebagian \\
\cline { 2 - 7 } & Pesan & 85 & 276 & 803 & 2498 & 5041 \\
\hline \multirow{2}{*}{$2 / 8$} & Berkas & Kembali & Sebagian & Sebagian & Sebagian & Sebagian \\
\cline { 2 - 7 } & Pesan & 85 & 236 & 705 & 2143 & 4325 \\
\hline \multirow{2}{*}{$3 / 8$} & Berkas & Kembali & Sebagian & Sebagian & Sebagian & Sebagian \\
\cline { 2 - 7 } & Pesan & 85 & 196 & 588 & 1783 & 3613 \\
\hline \multirow{2}{*}{$4 / 8$} & Berkas & Kembali & Sebagian & Sebagian & Sebagian & Sebagian \\
\cline { 2 - 7 } & Pesan & 85 & 157 & 468 & 1427 & 2896 \\
\hline \multirow{2}{*}{$5 / 8$} & Berkas & Kembali & Sebagian & Sebagian & Sebagian & Sebagian \\
\cline { 2 - 7 } & Pesan & 85 & 117 & 352 & 1067 & 2190 \\
\hline \multirow{2}{*}{$6 / 8$} & Berkas & Sebagian & Sebagian & Sebagian & Sebagian & Sebagian \\
\cline { 2 - 7 } & Pesan & 67 & 77 & 231 & 711 & 1474 \\
\hline \multirow{2}{*}{$7 / 8$} & Berkas & Sebagian & Sebagian & Sebagian & Sebagian & Sebagian \\
\cline { 2 - 7 } & Pesan & 31 & 36 & 109 & 350 & 736 \\
\hline
\end{tabular}

Tabel 5. Hasil pemotongan transposisi kolom 
(C2018 Ilmu Komputer Unila Publishing Network all right reserve

\begin{tabular}{clccccc}
\hline \multirow{2}{*}{$\begin{array}{c}\text { Pemotongan } \\
\text { Kanan }\end{array}$} & Hasil & \multicolumn{5}{c}{ Karakter } \\
\cline { 2 - 7 } & & 85 & 299 & 883 & 2838 & 5759 \\
\hline \multirow{2}{*}{$1 / 8$} & Berkas & Kembali & Sebagian & Sebagian & Sebagian & Sebagian \\
\cline { 2 - 7 } & Pesan & 85 & - & - & - & - \\
\hline \multirow{2}{*}{$2 / 8$} & Berkas & Kembali & Sebagian & Sebagian & Sebagian & Sebagian \\
\cline { 2 - 7 } & Pesan & 85 & - & - & - & - \\
\hline \multirow{2}{*}{$3 / 8$} & Berkas & Kembali & Sebagian & Sebagian & Sebagian & Sebagian \\
\cline { 2 - 7 } & Pesan & 85 & - & - & - & - \\
\hline \multirow{2}{*}{$4 / 8$} & Berkas & Kembali & Sebagian & Sebagian & Sebagian & Sebagian \\
\cline { 2 - 7 } & Pesan & 85 & - & - & - & - \\
\hline \multirow{2}{*}{$5 / 8$} & Berkas & Kembali & Sebagian & Sebagian & Sebagian & Sebagian \\
\cline { 2 - 7 } & Pesan & 85 & - & - & - & - \\
\multirow{2}{*}{$6 / 8$} & Berkas & Sebagian & Sebagian & Sebagian & Sebagian & Sebagian \\
\cline { 2 - 7 } & Pesan & - & - & - & - & - \\
\hline \multirow{2}{*}{$7 / 8$} & Berkas & Sebagian & Sebagian & Sebagian & Sebagian & Sebagian \\
\cline { 2 - 7 } & Pesan & - & - & - & - & - \\
\hline
\end{tabular}

Hasil pengujian pemotongan gambar membuktikan bahwa pemotongan berpengaruh pada pesan didalam stegoimage. Hasil pesan yang dapat dikembalikan oleh ciphertext RSA memiliki persentasi yang lebih baik dibandingkan dengan ciphertext transposisi kolom. Hal ini membuktikan bahwa ketahanan ciphertext RSA lebih baik saat terjadi pemotongan gambar.

Tabel 6. Pengiriman stegoimage melalui media sosial

\begin{tabular}{|c|c|c|c|c|c|c|c|c|c|c|}
\hline Media Sosial & $\begin{array}{l}\text { Dikirim } \\
\text { Sebagai }\end{array}$ & $\begin{array}{c}\text { Hasil } \\
\text { Pengiriman }\end{array}$ & Biru & Fullcolor & Grayscale & Hijau & Hitam & $\begin{array}{l}\text { Hitam } \\
\text { Putih }\end{array}$ & Merah & Putih \\
\hline \multirow{4}{*}{ Line } & \multirow{2}{*}{ Gambar } & Berkas & $\checkmark$ & $\checkmark$ & $\checkmark$ & $\checkmark$ & $\checkmark$ & $\checkmark$ & $\checkmark$ & $\checkmark$ \\
\hline & & Pesan & $\checkmark$ & $\checkmark$ & $\checkmark$ & $\checkmark$ & $\checkmark$ & $\checkmark$ & $\checkmark$ & $\checkmark$ \\
\hline & \multirow{2}{*}{ File } & Berkas & $\checkmark$ & $\checkmark$ & $\checkmark$ & $\checkmark$ & $\checkmark$ & $\checkmark$ & $\checkmark$ & $\checkmark$ \\
\hline & & Pesan & $\checkmark$ & $\checkmark$ & $\checkmark$ & $\checkmark$ & $\checkmark$ & $\checkmark$ & $\checkmark$ & $\checkmark$ \\
\hline \multirow{4}{*}{$\mathrm{BBM}$} & \multirow{2}{*}{ Gambar } & Berkas & $x$ & $x$ & $x$ & $x$ & $x$ & $x$ & $x$ & $x$ \\
\hline & & Pesan & - & - & - & - & - & - & - & - \\
\hline & \multirow{2}{*}{ File } & Berkas & $x$ & $x$ & $x$ & $x$ & $x$ & $x$ & $x$ & $x$ \\
\hline & & Pesan & - & - & - & - & - & - & - & - \\
\hline \multirow{4}{*}{ Whatsapp } & \multirow{2}{*}{ Gambar } & Berkas & $x$ & $x$ & $x$ & $x$ & $x$ & $x$ & $x$ & $x$ \\
\hline & & Pesan & - & - & - & - & - & - & - & - \\
\hline & \multirow{2}{*}{ File } & Berkas & $\checkmark$ & $\checkmark$ & $\checkmark$ & $\checkmark$ & $\checkmark$ & $\checkmark$ & $\checkmark$ & $\checkmark$ \\
\hline & & Pesan & $\checkmark$ & $\checkmark$ & $\checkmark$ & $\checkmark$ & $\checkmark$ & $\checkmark$ & $\checkmark$ & $\checkmark$ \\
\hline \multirow{4}{*}{ Telegram } & \multirow{2}{*}{ Gambar } & Berkas & $x$ & $x$ & $x$ & $x$ & $x$ & $x$ & $x$ & $x$ \\
\hline & & Pesan & - & - & - & - & - & - & - & - \\
\hline & \multirow{2}{*}{ File } & Berkas & $\checkmark$ & $\checkmark$ & $\checkmark$ & $\checkmark$ & $\checkmark$ & $\checkmark$ & $\checkmark$ & $\checkmark$ \\
\hline & & Pesan & $\checkmark$ & $\checkmark$ & $\checkmark$ & $\checkmark$ & $\checkmark$ & $\checkmark$ & $\checkmark$ & $\checkmark$ \\
\hline \multirow{4}{*}{$\begin{array}{l}\text { Facebook } \\
\text { Messanger }\end{array}$} & \multirow{2}{*}{ Gambar } & Berkas & $\checkmark$ & $\checkmark$ & $\checkmark$ & $\checkmark$ & $\checkmark$ & $\checkmark$ & $\checkmark$ & $\checkmark$ \\
\hline & & Pesan & $\checkmark$ & $\checkmark$ & $\checkmark$ & $\checkmark$ & $\checkmark$ & $\checkmark$ & $\checkmark$ & $\checkmark$ \\
\hline & \multirow{2}{*}{ File } & Berkas & $\checkmark$ & $\checkmark$ & $\checkmark$ & $\checkmark$ & $\checkmark$ & $\checkmark$ & $\checkmark$ & $\checkmark$ \\
\hline & & Pesan & $\checkmark$ & $\checkmark$ & $\checkmark$ & $\checkmark$ & $\checkmark$ & $\checkmark$ & $\checkmark$ & $\checkmark$ \\
\hline
\end{tabular}

Hasil pengujian menunjukkan bahwa tidak semua media sosial dapat mengirimkan stegoimage yang berisikan pesan. Hal ini dipengaruhi oleh masing-masing media sosial yang melakukan proses kompresi pada saat pengiriman gambar. Walaupun gambar dikirim dengan kualitas HD (High Definition) tidak menjamin pesan dapat dikirim dengan sempurna.

\section{KESIMPULAN}

Berdasarkan penelitian dan pengujian yang dilakukan dapat diambil kesimpulan sebagai berikut. 
1. Penggunaan ekstensi .JPG untuk mengurangi kecurigaan dapat dilakukan dengan mengubah ekstensi file stegoimage pada proses output stegoimage, tetapi tipe file tetap menggunakan tipe yang Loseless Compression.

2. Ukuran stegoimage yang dihasilkan oleh ciphertext transposisi kolom lebih kecil 1-2\% dibandingkan dengan stegoimage yang dihasilkan oleh ciphertext RSA.

3. Stegoimage yang berisi ciphertext RSA dan ciphertext transposisi kolom tidak dapat mengembalikan pesan setelah dilakukan perubahan brightness dan contrast, hal ini juga dipengaruhi oleh tipe file stegoimage adalah .JPG mengakibatkan penurunan ukuran stegoimage pada proses manipulasi.

4. Pemotongan bagian stegoimage tidak berpengaruh pada berkas yang tersimpan apabila dilakukan pada bagian bawah hingga 7/8 bagian. Pesan dengan 85 karakter dapat utuh setelah pemotongan stegoimage hingga 5/8 bagian dari kanan.

\section{DAFTAR PUSTAKA}

[1] Ahmad, E. I. 2016. Hibrid kriptografi dan steganografi menggunakan RSA dan AMELSBR. (Skripsi). Universitas Lampung. Bandar Lampung.

[2] Mollin, Richard A. 2007. An Introduction to Cryptography Second Edition Discrete Mathematics and Its Applications. Chapman \& Hall/CRC.

[3] Nosrati, Masoud. 2011. An introduction to steganography methods. World Applied Programming, Vol.1 No.3. ISSN: 2222-2510.

[4] Setiawan, Roni. 2016. Enkripsi Pesan dalam Media Gambar menggunakan Metode Hibrid Transposisi Kolom dan Adaptive Minimum Error Least Significant Bit Replacement (AMELSBR). (Skripsi). Universitas Lampung. Bandar Lampung.

[5] Lee, YK, and Chen, LH. An Adaptive Image Steganographic Model Based on MinimumError LSB Replacement. [Online]. Available: http://citeseer.ist.psu.edu/205600.html/lee99adaptive.pdf (1999).

[6] Wamiliana, Mustofa Usman, M. Azram, Faiz A. M. Elfaki, Astria Hijriani, and Pandya Panditatwa. 2015. Adaptive Minimum Error Least Significant Bit Replacement Method for Steganography using JPG/JPEG and PNG Files. Science International (Lahore), Vol.27 No.6, hal $4987-4990$. 